\title{
A RBMFC e o desafio da educação médica continuada
}

\author{
The RBMFC and the challenge of continuing medical education \\ La RBMFC y el desafío de la educación médica continuada
}

Armando Henrique Norman. Mestre em Antropologia Médica pela University of Durham, Reino Unido. Especialista em MFC. editor.rbmfc@sbmfc.org.br

Imagine um país cujas escolas médicas não ensinam sistematicamente a seus estudantes a disciplina clínica na qual a maioria deles irá atuar. Imagine que tal país também falhe em conduzir pesquisas sobre problemas clínicos e organizacionais que tanto pacientes como médicos enfrentam dentro dessa disciplina. Embora isso seja impensável atualmente, o Reino Unido era assim quando o NHS começou.

Frank Sullivan ${ }^{1}$

Chair, Heads of Departments Group SAPC Society for Academic Primary Care

Este primeiro editorial de 2013 traz uma reflexão sobre educação médica e a importância da disciplina de Medicina de Família e Comunidade como estratégia para o fortalecimento e expansão da APS/ESF. No Brasil, a educação médica direcionada para a medicina de família apresenta um sério problema em sua origem: a quase ausência de departamentos de Medicina de Família e Comunidade nas universidades públicas. Países como Canadá, Estados Unidos e Inglaterra deram início a esse processo - mais sistematicamente na década de 1960 - com a introdução da disciplina Medicina de Família nos currículos dos cursos de graduação em Medicina, bem como com a criação dos respectivos departamentos em suas universidades ${ }^{2}$.

Esse movimento, muito importante internacionalmente, atingiu seu ápice na década de 1970 (considerada a "fase de ouro" da medicina geral e familiar no Reino Unido $)^{3}$ e resultou na criação da WONCA, em $1972^{2}$. Foi também na década de 1970 que surgiram os primeiros programas de residência em Medicina Geral e Comunitária no Brasil. No entanto, essas iniciativas permaneceram em estado de latência, uma vez que o ambiente político do Brasil, com o golpe militar, não favorecia seu desenvolvimento ${ }^{4}$. Somente duas décadas depois é que a MFC retoma sua força, através do Programa Saúde da Família, em 1994. Esse contexto histórico produziu uma "solução de continuidade" em que os profissionais mais necessários para o SUS/APS não fazem parte oficialmente do ambiente acadêmico dos cursos de Medicina.

Richardson ${ }^{5}$ aponta quatro critérios para a inclusão da MFC como disciplina acadêmica: 1) Perfil de morbidade (85\% dos casos são "resolvidos" na APS); 2) Técnica de análise (transcende o modelo biomédico, contextualizando a pessoa, a família e a comunidade); 3) Filosofia (os MFC não estão vinculados a um órgão ou sistema - cardiologia, psiquiatria -, nem a uma tecnologia - radiologia) ${ }^{6}$; e 4) Pesquisa (o ambiente da APS e a prática da MFC propiciam um vasto campo de pesquisa, que difere dos níveis de atenção secundário e terciário). Para Howie ${ }^{7}$ citando Pereira Gray, "uma área se torna uma disciplina acadêmica quando possui sua própria literatura".

Como citar: Norman AH. A RBMFC e o desafio da educação médica continuada. Rev Bras Med

Fam Comunidade. 2013;8(26):3-5. Disponível em: http://dx.doi.org/10.5712/rbmfc8(26)719 
É notório que existe um esforço e incentivos por parte do MEC para que na reforma curricular do curso de Medicina haja a inserção precoce dos alunos nos serviços de APS/ESF. Essa tendência relativamente recente de unificar serviços de saúde e universidades tem contribuído tanto para que os recém-formados escolham a APS/ESF como campo de atuação profissional como também para a produção acadêmica em APS. Por exemplo, esta edição traz o relato de experiência Conhecimento sobre hanseniase de contatos intradomiciliares na Atenção Primária em Ananindeua, Pará, Brasil que retrata estudantes de graduação sendo estimulados a irem às comunidades e a pensarem a APS brasileira. Porém, esse movimento centrífugo precisa estar acompanhado de uma iniciativa centrípeta: trazer oficialmente para dentro das universidades os profissionais dos serviços de APS/ESF sem que esses profissionais deixem suas práticas clínicas. Esse seria um passo fundamental para o fortalecimento da APS, pois o contato do aluno de graduação com profissionais dessa área ou especialidade durante seu processo de formação (tanto no ambiente universitário como na prática nas unidades de saúde da família) favoreceria a criação de uma identidade profissional vinculada à APS/ESF e à MFC.

Essa situação também se reflete um pouco na própria Revista Brasileira de Medicina de Família e Comunidade (RBMFC), que apesar de pertencer à Sociedade Brasileira de Medicina de Família e Comunidade (SBMFC) tem seu conteúdo tradicionalmente voltado para uma plêiade de profissionais de saúde e gestores do SUS, com um perfil que se aproxima mais da saúde pública e/ou coletiva, com pouca ênfase na prática da MFC. Isso em parte é um reflexo desse processo histórico, acadêmico e institucional, devido à pequena influência da MFC na formação em Medicina.

No sentido de contribuir para a Medicina de Família e Comunidade enquanto disciplina acadêmica, nesta edição 26 a RBMFC anuncia uma modesta porém importante iniciativa para a educação médica continuada dos MFC. A partir das edições subsequentes, a RBMFC disponibilizará uma nova seção denominada Artigos de Revisão Clínica. Espera-se, desse modo, fortalecer a educação continuada e permanente dos profissionais da ESF, principalmente médicos e enfermeiros. Os artigos para essa seção deverão ser elaborados de acordo com o guia para artigos de revisão clínica, já disponível no site da RBMFC. Não se trata de "reinventar a roda" mas de adotar critérios semelhantes a outros periódicos científicos internacionais, tais como o Journal of American Academy of Family Physicians, que há muito tempo vem produzindo um conteúdo mais direcionado para a prática da MFC.

A revista adotará basicamente dois eixos: um primeiro eixo que continuará estimulando o processo tradicional da política de fortalecimento e aprimoramento da própria APS/ESF (através de pesquisas na área), materializado em artigos originais, relatos de experiências e revisôes sistemáticas; e um segundo eixo voltado para a produção de artigos de atualização clínica, ou seja, revisôes clínicas baseadas em evidências sobre temas pertinentes para a prática dos profissionais das equipes de saúde da família, principalmente médicos e enfermeiros. Essa nova seção também pretende ser um espaço para estimular os residentes em MFC a direcionarem seus trabalhos de conclusão de curso (TCC) para um tema clínico específico, comum e importante para a APS/ESF, com potencial para ser publicado na revista da especialidade.

Nesse processo de renovação, todas as seçóes da revista foram revisitadas para deixar os textos mais claros e melhor destacar a estrutura dos textos de cada seção. Assim, pensando longitudinalmente, espera-se fortalecer este periódico e torná-lo mais atrativo para profissionais e acadêmicos da APS, sem perder seu ecletismo.

Essa proposta vem somar esforços com a SBMFC, que tem fomentado as ligas acadêmicas como estratégia para atrair alunos de graduação para a MFC. Por exemplo, esta edição traz um relato de experiência do Grupo de Medicina de Família e Comunidade de Santos, em que um coletivo de estudantes busca criar um espaço onde a especialidade possa florescer. A importância de o médico de família estar presente (fazendo um contraponto) dentro dos cursos de Medicina pode ser vista em dois artigos: na seção Espaço Aberto é explorada a temática do afeto na atividade profissional do MFC, enquanto que na seçấo Perspectiva é discutido de modo bastante interessante o tema do rastreamento do câncer de mama.

Por fim, dada a complexidade do cenário de prática da medicina rural, em que o médico de família tem papel central, está sendo publicado juntamente com esta primeira edição o suplemento da WONCA Rural, que contém documentos importantes, elaborados pela WONCA, traduzidos pelos membros do GT de Medicina Rural da SBMFC, coordenados pelo Dr. Leonardo Targa. Este suplemento vem em momento oportuno, visto que o Brasil sediará o Congresso Mundial da WONCA Rural em 2014. Assim, o leitor poderá se inteirar sobre o que se está discutindo em termos de medicina rural no Brasil e no mundo. Portanto, uma boa leitura a todos e que gradualmente a RBMFC possa cada vez mais ocupar um lugar de destaque no meio acadêmico e profissional da APS brasileira. 


\section{Referências}

1. Sullivan F. Preface. In: Howie JGR, Whitfield M. Academic General Practice in the UK Medical Schools, 1948-2000: a short history. Edinburgh: Edinburgh University Press; 2011.

2. McWhinney IR. A textbook of Family Medicine. New York: Oxford University Press; 1989.

3. Laing AW, Marnoch G, McKee L, Joshi R. Administration to innovation: the evolving management challenge in primary care. J Manag Med. 1997; 11(2): 71-87. http://dx.doi.org/10.1108/02689239710177701

4. Falk JW. A Medicina de Família e Comunidade e sua entidade nacional: histórico e perspectivas. Rev Bras Med Fam Com. 2004; 1(1): 5-10

5. Richardson IM. The value of university department of general practice. BMJ. 1975; 4(5999): 740-2. http://dx.doi.org/10.1136/bmj.4.5999.740

6. McWhinney IR. The importance of being different. Br J Gen Pract. 1996; 433-436.

7. Howie JGR, Whitfield M. Academic General Practice in the UK Medical Schools, 1948-2000: a short history. Edinburgh: Edinburgh University Press; 2011. p. 137. http://dx.doi.org/10.3366/edinburgh/9780748643561.001.0001 